\section{Granula, azurophile}

H. Baum

Institut für Laboratoriumsmedizin, Mikrobiologie und Blutdepot, Regionale Kliniken Holding RKH GmbH, Ludwigsburg, Deutschland

\section{Synonym(e) Azurgranula}

Englischer Begriff azurophil granules

Definition Mit Azur-Eosin-Methylenblau ( $\triangleright$ Giemsa-Lösung) sich anfärbende purpurrote, intrazytoplasmatische Körperchen der neutrophilen Granulozyten.

Beschreibung Bei den azurophilen Granula handelt es sich um die primären Lysosomen vom Typ 1. Das sind Abspaltungen des rauhen endoplasmatischen Retikulums, die in erster Linie lysosomale Enzyme und Peroxidasen enthalten. Bei den über 50 verschiedenen Enzymen, die bisher in primären Lysosomen nachgewiesen wurden, handelt es sich vor allem um die sauren Hydrolasen (saure Phosphatase [Leitenzym], $\alpha$-Aminopeptidase und andere Proteasen, $\beta$-Glukuronidase, Esterasen, Sulfatasen, Desoxyribonukleasen, Ribonukleasen, Kathepsin D, Kollagenasen, Triglyzeridlipasen, Neuraminidasen, Phospholipasen, - Sphingomyelinase, Glukosidase, $N$-Acetyl-Hexosaminidase und Hyaloronidase). Diese Enzyme haben ihr Wirkungsoptimum im sauren Bereich bei einem $\mathrm{pH}$ 4-5. Die primären Granula dienen vor allem dem intrazellulären Abbau von zellfremden organischen Substanzen (Heterophagie bzw. Fremdkörperabwehr), die von der Zelle durch Endozytose aufgenommen wurden, aber auch dem Abbau von zelleigenem Material (Autophagie von Zellorganellen).

\section{Literatur}

Smolen JE, Boxter LA (2001) Function of neutrophils. In: Lewis SM, Bain BJ, Bates I (Hrsg) Practical haematology, 9. Aufl. Churchill Livingstone, London, S 781-782 